\title{
COLISIÓN DE LA LEY PENAL Y LA COSTUMBRE EN LOS DELITOS DE VIOLACIÓN SEXUAL A MENORES DE EDAD COMETIDOS POR LOS INTEG RANTES DE LAS COMUNID ADES NATIVAS DE LA CUENCA DEL RÍO AMAZONAS
}

\author{
Jorge Cueva Zavaleta*
}

\begin{abstract}
Resumen:
La presente investigación parte de la necesidad de dejar al descubierto el problema jurídico que se suscita al aplicar la Ley Penal de la cultura mayoritaria mestiza en las comunidades nativas del río Amazonas, colisionando con sus costumbres ancestrales que rigen su forma de vida, y de esta manera lograr que se legisle en forma descentralizada teniendo en cuenta sus propios organismos de resolución de conflictos.

Palabras Clave: Comunidad nativa - costumbre - multiculturalidad

A bstract:

This present research is made from the necessity of leaving uncover the legal issue which is generated when criminal law of the majority mixed race culture is applied over the native communities from the A mazon River basin, colliding with their ancient customs which underlie their living style. Thus we propose decentralized legislation based on their own organisms to solve conflicts.
\end{abstract}

Key words: Native communities - customs - Multiculturality.

\section{Sumario:}

1. Introducción. 2. Material y métodos. 3. Resultados. Discusión.

4. Conclusiones.

* Vocal Titular de la CorteSuperior de usticia de La Libertad y Ex-docente de pre y postgrado de Derecho en la Universidad Nacional de Trujillo. 
Jorge Cueva Zavaleta - Colisión de la ley penal y la costumbre en los delitos de violación sexual a menores de edad cometidos por los integrantes de las comunidades nativas de la cuenca del río Amazonas

\section{INTRODUCCIÓN}

\section{A ntecedentes del problema:}

La Constitución Política del Perú reconoce el derecho de las personas a su identidad cultural, así como a la existencia de las comunidades campesinas y nativas. Estos Derechos están establecidos en el artículo 2으, inciso 19 y en el artículo 890 de la carta fundamental. El Perú, como país multicultural, tiene una población conformada por diferentes culturas con sus propias costumbres, las mismas quese encuentran asentadas en sus diversas regiones natural es. Así tenemos, los Mestizos (mayoría) en la Región Costa; Indígenas (mayoría) en la Región Sierra; Mestizos (mayoría) y Nativos (minoría) en la Región Selva.

Según la Carta Magna, todos somos iguales ante la Ley, sin embargo, su aplicación no tiene en cuenta nuestra realidad nacional; por un lado están los Mestizos inmersos en los adelantos científicos de las grandes ciudades y, por otro lado, olvidados, abandonados y al borde de la extinción los miembros de las comunidades nativas de la cuenca del río A mazonas.

Una de las costumbres ancestrales de las comunidades nativas es el inicio temprano de la vida sexual de sus mujeres, a pesar de ello, los nativos (al igual quelos mestizos) son procesados por la comisión del delito deviolación sexual demenores deedad, por el sólo hecho de convivir con menores desu propia comunidad.

Los miembros de las comunidades nativas se rigen por sus propias costumbres y es en la propia comunidad donde resuelven los problemas social es que se presentan; sin embargo, el Estado ha establecido que están exentos de responsabilidad sólo cuando haya error de comprensión culturalmente condicionado (conforme lo establece el Código Penal en su artículo 159), pero no ha tenido en cuenta quelos nativos no actúan por error sino por su modo de vida ancestral.

Actual mente, no se encuentran trabajos de investigación relacionados con la problemática suscitada con la aplicación de la Ley Penal en los delitos de violación sexual de menores de edad que se imputa a los miembros de las comunidades nativas del Río A mazonas, sin tener en cuenta sus costumbres ancestrales. 
Jorge Cueva Zavaleta - Colisión de la ley penal y la costumbre en los delitos de violación sexual a menores de edad cometidos por los integrantes de las comunidades nativas de la cuenca del río Amazonas

\section{Justificación:}

La Investigación se justifica por que no se respeta las costumbres ancestrales de los nativos de la cuenca del río A mazonas, quienes son procesados tan igual como los otros miembros dela población peruana, con una legislación penal unitaria, centralista y urbanista e incluso sin respetar su idioma y hábitat natural. Con esta investigación se persigue dejar al descubierto el problema jurídico que se suscita al aplicar la Ley Penal en las comunidades nativas del río A mazonas, que colisiona con sus costumbres ancestrales y de esta manera lograr que se legisle en forma descentral izada, dejando a un lado el aforismo constitucional "todos somos iguales ante la Ley", por lo menos en lo que respecta al ámbito penal.

\section{Planteamiento del Problema:}

De la problemática antes expuesta, se planteo el siguiente problema de investigación:

¿Colisiona Ia Ley Penal con la Costumbre cuando se aplica en los delitos de violación sexual de menores cometidos por los integrantes de las Comunidades $\mathrm{N}$ ativas de la cuenca del río A mazonas?

\section{M arco Teórico}

\subsection{La M ulticulturalidad en el Perú}

El Multiculturalismo, es la primera expresión del pluralismo cultural, que promueve la no discriminación por razones de raza o cultura, la celebración y reconocimiento dela diferencia cultural así como el derecho a ella. Empero, como lo sostiene Hurtado, el Estado Liberal frente al Multiculturalismo adoptó en un primer momento la estrategia de la tolerancia, entendida como "no criminalización" de las actuaciones de los miembros de minorías, en tanto no atentaran contra la cultura mayoritaria y cumplieran sus obligaciones legales ${ }^{1}$. El Perú es un país multicultural y plurilingüe en el que coexisten más de 65 grupos étnicos en costa, andes y amazonía. Los pueblos amazónicos, fueron impelidos a organizarse de forma nuclear, en comunidades denominadas "nativas", para adecuarse a la legislación de entonces. Diversos estudios señalan a las Comunidades, Campesinas y Nativas, como el sector de mayor pobreza y exclusión en el país, lo cual ha 
Jorge Cueva Zavaleta - Colisión de la ley penal y la costumbre en los delitos de violación sexual a menores de edad cometidos por los integrantes de las comunidades nativas de la cuenca del río Amazonas

implicado su poca participación en la sociedad y la restricción en el ejercicio de sus derechos. Para los pueblos nativos (e indígenas), desde distintas cosmovisiones y perspectivas particulares, el territorio es vital, no sólo para su supervivencia, sino por los lazos ancestrales que le dan fuerza y cohesión social y cultural al grupo. El territorio nativo e indígena es comprendido como la totalidad del hábitat de un pueblo, es decir desdeel punto de vista geográfico integra no sólo la superficie terrestre, las aguas y el subsuelo sino que desde el punto de vista cultural abarca el espacio en el cual la cultura de un pueblo se asienta y reproduce.

\subsection{La Interculturalidad}

Según Malgesisni y Giménez, la aparición del término interculturalidad o interculturalismo parece motivada por las carencias de los conceptos de multicultural idad y multiculturalismo para reflejar la dinámica social y para formular el objetivo de nuevas síntesis socioculturales². Uno de los debates que origina la I nterculturalidad es el hecho deque la interacción no se da la mayoría de veces en un plano de igualdad sino la desigualdad, dominio y jerarquías etnoraciales, junto con los sistemas de estratificación de clases y género. También se debate como se puede construir una nueva síntesis cuando los grupos que deben participar en ello son por lo general grupos dominantes o dominados, mayorías o minorías. Para el sentido común las adscripciones del término etnicidad o raza dependen de las cualidades grupales inherentes; de este modo en diversos países latinoamericanos, "indígenas", "afro americanos", descendientes de esclavos entre otros, e inmigrantes, emergen como colectivos discretos cuyo perfil diferenciado se anclaría en una materia que torneada por la historia, la cultura, el color o la lengua generaría una sombra propia en el cuerpo transparente de naciones como Estado que, basadas en valores "universales" comunes, no proyectarían sombra particular alguna.

\subsection{Las Comunidades $\mathrm{N}$ ativas de la Cuenca del Río Amazonas}

De la investigación plasmada en el libro "Amazonía Peruana, Comunidades Indígenas, Conocimientos y Tierras Tituladas" - GEF/ PNUB/ ONUPS, en nuestra A mazonía habitan 42 grupos étnicos las que pertenecen a 13 familias lingüísticas y desde 1950 hasta el día de hoy se han extinguido 11 etnias y 18 más ven peligrar su existencia por la destrucción progresiva de su hábitat³. 
Jorge Cueva Zavaleta - Colisión de la ley penal y la costumbre en los delitos de violación sexual a menores de edad cometidos por los integrantes de las comunidades nativas de la cuenca del río Amazonas

Estas comunidades desarrollan su existencia en zonas ecológicas claramente identificables: bosques secos tropicales, bosques húmed os subtropicales y bosques húmedos tropicales dispersos en grandes cuencas hidrográficas. Algunas comunidades son identificadas con otros nombres como en el caso delos pueblos de Lamas, Tabal osos y N uyupampa, cuyos habitantes fueron llamados Motilones cuando fueron conquistados por los Incas en el año $1460^{4}$.

\subsection{EI D erecho Penal y La Costumbre}

\subsubsection{La Costumbre:}

El concepto de costumbre es objeto de polémica entre los juristas. En su acepción más propia, la costumbre se distingue claramente de los usos social es y de la jurisprudencia. Supone la costumbre una conducta general y repetida de un medio social o territorial que ésteconsidera jurídicamente obligada, es decir que practica- al menos cuando se consolida la costumbre, aunque inicialmente no fuera así- en la idea de estar ajustándose a una norma jurídica. Se distingue claramente de los usos sociales en que su violación acarrea una responsabilidad de tipo jurídico y no de mera reprobación social. No hay que confundir tampoco la costumbre con la Jurisprudencia, es decir, con los criterios mantenidos, aunque sea de modo reiterado y constante, por los tribunales en la interpretación de las leyes. La jurisprudencia, aún siendo reiterada, sólo podría asimilarse a la costumbre cuando consagra usos y prácticas anteriores, más no cuando los jueces arbitran y repiten una solución racional, por que ni ellos representan necesariamente la convicción jurídica de la comunidad circunstante, ni son ellos mismos quienes practican la regla como vinculante en propias incumbencias, sino que lo entienden existente para otro.

El principio de legal idad excluyela posibilidad decrear delitos, aplicar penas o agravarlas en basea la costumbre (nullum crimen, nulla poena sinelegescripta). La costumbre es más que la reiteración permanente de determinadas conductas, creando en los ciudadanos una conciencia de obligatoriedad. Este derecho consuetudinario está formado por dos presupuestos esencial es: un elemento subjetivo (el animus), quees la voluntad de vigencia, por partedela comunidad, hacia una conciencia o sentimiento obligacional; y un el emento objetivo (el corpus), que es la práctica suficientemente reiterada de un determinado acto. A la costumbre la podemos identificar de manera activa (consuetudo), cuando da nacimiento a nuevas normas jurídicas o normas 
Jorge Cueva Zavaleta - Colisión de la ley penal y la costumbre en los delitos de violación sexual a menores de edad cometidos por los integrantes de las comunidades nativas de la cuenca del río Amazonas

consuetudinarias; y demanera pasiva (desuetudo), cuando extingue o poneen obsolescencia al gunas normas jurídicas preexistentes.

\subsubsection{Relación de la Costumbre con la Ley}

En cuanto a la relación que puedetener la costumbre con la ley, sedistinguen tres formas: a) Costumbre praeter legem, quees aquella que se perfila más allá de lo establecido por la ley. No tiene validez, ya que atenta contra toda expresión del principio de legalidad. b) Costumbre contra legem, que actúa en forma contraria a lo establecido por la ley. A sí, si existe un conflicto entre ley y costumbre, se elegirá a la costumbre. También se vulnera el principio de legalidad. c) Costumbresecundum legem (costumbreintegrativa) que está en concordancia con lo expresado por la ley. La ley se remite a la costumbre para solucionar los problemas de interpretación o vacíos que pueda encontrar el operador de Derecho. Con esta forma de costumbre se busca la concordancia con lo expresado por la ley, y con ello no se tendría ningún tipo de contrariedad con el principio de legalidad.

\subsubsection{La Costumbre en el Perú}

En el Perú, el derecho consuetudinario ocupa un lugar al lado del derecho Penal Formal. Si bien, Ia Constitución Política prohíbetoda forma de justicia paral ela (con excepción de la arbitral y militar), también admite la llamada jurisdicción especial ejercida por las autoridades de las comunidades campesina y nativas con el apoyo de las rondas campesinas dentro de su ámbito territorial deconformidad con el derecho consuetudinario y siempre que no violen los derechos fundamentales de las personas. Según Villavicencio, se considera que esta concepción de una justicia unitaria es evidente para una idiosincrasia europea moderna, mas no para Estados con fuertes derechos consuetudinarios locales y étnicos y sistemas informales de justicia ${ }^{5}$.

\subsubsection{La ley penal peruana y las costumbres de las culturas amazónicas}

Las culturas nativas mantienen sus costumbres y tradiciones a pesar de la intromisión de la cultura mestiza, como así se ha establecido con la investigación llevada a cabo por el Centro deSalud Pública dela Universidad Peruana Cayetano Heredia, con el auspicio de la Organización de las Naciones Unidas para la A gricultura y la A limentación - FAO -, que realizó entre los meses de octubre de 1994 y junio de 1995 el proyecto “Educación en 
Jorge Cueva Zavaleta - Colisión de la ley penal y la costumbre en los delitos de violación sexual a menores de edad cometidos por los integrantes de las comunidades nativas de la cuenca del río Amazonas

población para la promoción de lideres juveniles rurales de la selva del Perú", en la amazonía peruana. En dicha investigación se determinó que "La iniciación sexual es a temprana edad. En promedio ocurre a los 14 años de edad, aunque se encuentran numerosos casos a los 12 años. En comunidades nativas de Shipibo-Conibo se encuentra que el $2.3 \%$ de las adolescentes de 12 a 14 años ya son madres, y en casos de los Yaguas, el $40 \%$ de las adolescentes y jóvenes de 15 a 19 años también son madres" ${ }^{6}$. El Censo Nacional de Población y Vivienda de 1993, ubicó a Loreto entre los 10 departamentos en que la tasa de fecundidad de adolescentes variaba de $15 \%$ al $20 \%$. Esto contrasta con el caso de Lima y Callao que no excede del $4 \%$. De acuerdo a lo anterior se puede inferir que las zonas más afectadas por la iniciación sexual y maternidad tempranas se encuentran en los afluentes del río A mazonas, en las comunidades nativas.

En el siglo pasado, en un comienzo, se propugnaba un Derecho Penal Especial para los integrantes de las comunidades nativas e indígenas por pertenecer a una cultura diferente, luego apareció la propuesta de legislar en base a la peligrosidad del nativo; posteriormente sobre la base de la inimputabilidad por su cultura o costumbre. Siguiendo a Villavicencio, la responsabilidad penal de personas con pautas de culturas diferentes ha sido tratada en diferentes sentidos por el Derecho Penal peruano ${ }^{7}$. Así tenemos queel Código de 1924 contenía una clara concepción etnocentrista que desconocía el derecho de las autonomías culturales. Los sujetos tenían la condición de imputables relativos, susceptibles de una penalidad atenuada o medidas de seguridad. De esta manera, el ordenamiento penal concebía a la sociedad integrada por salvajes, semicivilizados y civilizados en una explicación de desarrollo unilineal inevitable que en la actualidad ha sido desvirtuada a favor de una explicación multilateral con el Código Penal Peruano de 1991, queen su artículo 15o incorporó a la legislación una nueva fórmula de error (de comprensión culturalmentecondicionado).

Por otro lado, sin perjuicio de sus costumbres ancestral es que rigen su vida diaria, como la convivencia sexual con menores de edad, investigaciones real izadas con los aguarunas por parte deautores como Peña, han mostrado queen dichas comunidades existen organismos de resolución deconflictos del conjunto de los comuneros ${ }^{8}$. Cuentan con una directiva y como órgano máximo: una A samblea Comunal para resolver asuntos de robos, adulterio, incesto, venganza, etc. A demás existe un jefe de justicia nativa que integra un determi nado grupo de comunidades aguarunas, asumiendo competencia sobreconflictos queno son resuel tos al interior dela comunidad, por ejemplo, 
Jorge Cueva Zavaleta - Colisión de la ley penal y la costumbre en los delitos de violación sexual a menores de edad cometidos por los integrantes de las comunidades nativas de la cuenca del río Amazonas

en casos de homicidio por brujería o venganza. Así, la relación homicidio con la cosmovisión andina puede presentar diversas facetas vinculadas a la cultura. La situación de escasez de recursos naturales originada en la pobreza del suelo en el que habitan guarda relación con los infanticidios selectivos en grupos amazónicos aislados; también la idea de responsabilidad de grupo en el sentido quecual quier pariente del fallecido puede dar muertea cual quier otro pariente del homicida, tiene una relación con la necesidad de equilibrio en una sociedad que no cuenta con un poder centralizado y quesólo puedearribar a esefin demanera privada. En al gunos idiomas aborígenes, una misma palabra es usada para expresar los conceptos occidentales de justicia y venganza.

\subsubsection{El Artículo 150 del Código Penal y el Error de Comprensión Culturalmente Condicionado}

En nuestra legislación existe una forma de error especial denominada "error de comprensión culturalmente condicionado" tipificado en el artículo $15^{\circ}$ del Código Penal. Esteerror se presenta cuando el infractor se desarrolla en una cultura distinta a la nuestra y ha internalizado desde niño las pautas de conducta de esa cultura. Según Martínez, el problema que representa a continuación esta vinculado al de la diversidad étnica cultural, propio de las sociedades latinoamericanas (las cuales albergan en su seno un sin número de culturas minoritarias quea su vez reclaman un reconocimiento a su identidad cultural) ${ }^{9}$.

Para los casos en queel condicionamiento cultural o la costumbre no provenga de un error de parte del sujeto sino como especial motivación, es viable fundamentar la inexigibilidad en base al artículo 45 으umeral 2 del Código Penal, no obstante ello este articulo no establece expresa posibilidad de exención de pena sino que se deja a la discrecionalidad jurídicamente vinculada del juez sobre la base del principio de determinación de la pena para sancionar como un agente doloso. La intencionalidad de los legisladores, al regular el artículo 150 del Código Penal, fuela deconsiderar la inimputabilidad o inculpabilidad en la comisión de algún ilícito penal dequienes forman parte de otras culturas minoritarias. Al respecto, Hurtado Pozo sostiene que esta manera de elaborar el artículo 150 demuestra queno se reflexionó sobre la oportunidad y necesidad de incorporar una disposición de esta naturaleza en la ley, ni sobre los efectos desu aplicación. A pesar delas buenas intenciones de sus autores, resulta en efecto incorrecto calificar la exención de irresponsabilidad penal prevista en el artículo 15o 
Jorge Cueva Zavaleta - Colisión de la ley penal y la costumbre en los delitos de violación sexual a menores de edad cometidos por los integrantes de las comunidades nativas de la cuenca del río Amazonas

de error de comprensión culturalmentecondicionado ${ }^{10}$. Por otro lado, en la Doctrina Nacional no hay uniformidad de criterios sobre la naturaleza jurídica de esta institución, por un lado hay autores que consideran que es una causa de inculpabilidad (como el caso de Villa Stein y Bramont A rias Torres) y otros como causa de inimputabilidad (como Villavicencio Terreros y Hurtado Pozo); sin embargo, lo que esta en cuestión es el hecho de quelos indígenas o nativos no actúan por patrones extraños a su comunidad sino de acuerdo a sus costumbres y tradiciones. Lo que se exige, por parte de la cultura mayoritaria, es que los miembros de dichas culturas se comporten de acuerdo a los cánones del mundo occidental gl obalizado en desmedro de sus costumbres ancestrales. Ello ha motivado que se procesen y condenen por igual a mestizos y nativosque incurren en el delito deviolación sexual de menores de edad. Incluso Villavicencio, considera que en dicho artículo se diferencia dos modalidades de condicionamiento: Por su cultura y costumbre. El primero es el error decomprensión cultural mentecondicionado (que es un error invencible de prohibición) y el segundo correspondería a la Ilamada conciencia disidente: (cuando el nativo actúa en el marco de su entorno cultural que no considera su conducta como ilícita lo que sería un error vencible) ${ }^{11}$.

\section{Hipótesis:}

Frenteal problema planteado se formuló la siguiente hipótesis de trabajo:

"La Ley Penal colisiona con la costumbre cuando se aplica en los delitos de violación sexual de menores cometidos por los integrantes delas $C$ omunidades $\mathrm{N}$ ativas de la cuenca del río A mazonas, sin respetar sus costumbres ancestrales que rigen su forma de vida"

\section{MATERIAL Y MÉTODOS}

\section{M aterial de Estudio}

\subsection{Población:}

La población estuvo conformada por todas las comunidades nativas de la cuenca amazónica, con sus costumbres ancestrales y los procesos instaurados contra sus miembros por el delito de violación de menores de edad, por su convivencia con menores de edad, así como los procesos seguidos contra la población mayoritaria mestiza por el mismo delito. 
Jorge Cueva Zavaleta - Colisión de la ley penal y la costumbre en los delitos de violación sexual a menores de edad cometidos por los integrantes de las comunidades nativas de la cuenca del río Amazonas

\subsection{M uestra}

La muestra estuvo conformada por el $25 \%$ de las comunidades nativas de la cuenca amazónica, como son: A chuar, Bora, A sháninka, A guaruna, Shi piboConibo, Jíbaro, Quechua- Lamista, Quechua del Napo, Quechua del Pastaza y del Tigre, Amuesha, Huitoto, Yagua y Nomatsiguenga y los procesos instaurados contra los miembros de las comunidades nativas y mestizos por la comisión del delito de violación sexual de menores de edad.

\section{M étod os y Técnicas:}

\subsection{M étodo}

Se aplicó el método Análisis - Síntesis, para el estudio de los datos obtenidos sobre las costumbres ancestrales de las comunidades nativas de la cuenca del río A mazonas, sus derechos fundamentales, la Ley Penal que regula el delito de violación sexual demenores deedad, así como los procesos penales instaurados contra mestizos y nativos por el delito antes anotado.

El diseño de contrastación utilizado fue el de dos grupos: El conformado por comunidades nativas con sus costumbres ancestrales que rigen su forma de vida y el conformado por los procesos instaurados contra nativos y mestizos por el delito de violación sexual de menores de edad.

\section{OBSERVACIÓN}

$25 \%$ de las comunidades nativas con sus costumbres ancestrales que rigen su forma de vida (convivencia con menores de edad) y sus derechos fundamentales.

Procesos penales seguidos contra mestizos y nativos en la Corte Superior de Loreto y La Libertad por el delito de Violación sexual de menores de edad.

Periodo 2006 - 2007.

\subsection{Técnicas}

Se utilizó la observación, la encuesta, la entrevista y el fichaje para la recolección de datos, cuyos instrumentos son las hojas de registro, fichas, cuadernillos de encuestas y entrevistas. 
Jorge Cueva Zavaleta - Colisión de la ley penal y la costumbre en los delitos de violación sexual a menores de edad cometidos por los integrantes de las comunidades nativas de la cuenca del río Amazonas

\section{III.RESULTAD OS:}

CUADRO № 1. Muestra de 51 personas encuestadas que laboraron en Comunidades Nativas, confirmando la edad que comienzan a tener Relaciones Sexuales, en el Departamento de San Martín, Provincia de Lamas, en Enero de 2007.

\begin{tabular}{|c|c|c|}
\hline $\begin{array}{c}\text { Edad de las Nativas que comienzan } \\
\text { a tener Relaciones Sexuales }\end{array}$ & $\begin{array}{c}\text { No Personas } \\
\text { Encuestadas }\end{array}$ & Porcentaje \\
\hline 10 Años & 25 & 49.02 \\
\hline 11 Años & 10 & 19.61 \\
\hline 12 Años & 15 & 29.41 \\
\hline 13 Años & 0 & 0.00 \\
\hline 14 Años & 1 & 1.96 \\
\hline TOTAL & 51 & 100.00 \\
\hline
\end{tabular}

FUENTE: Encuesta de 51 personas que Iaboraron en Comunidades $\mathrm{N}$ ativas de San Martín (Lamas - Motilones)

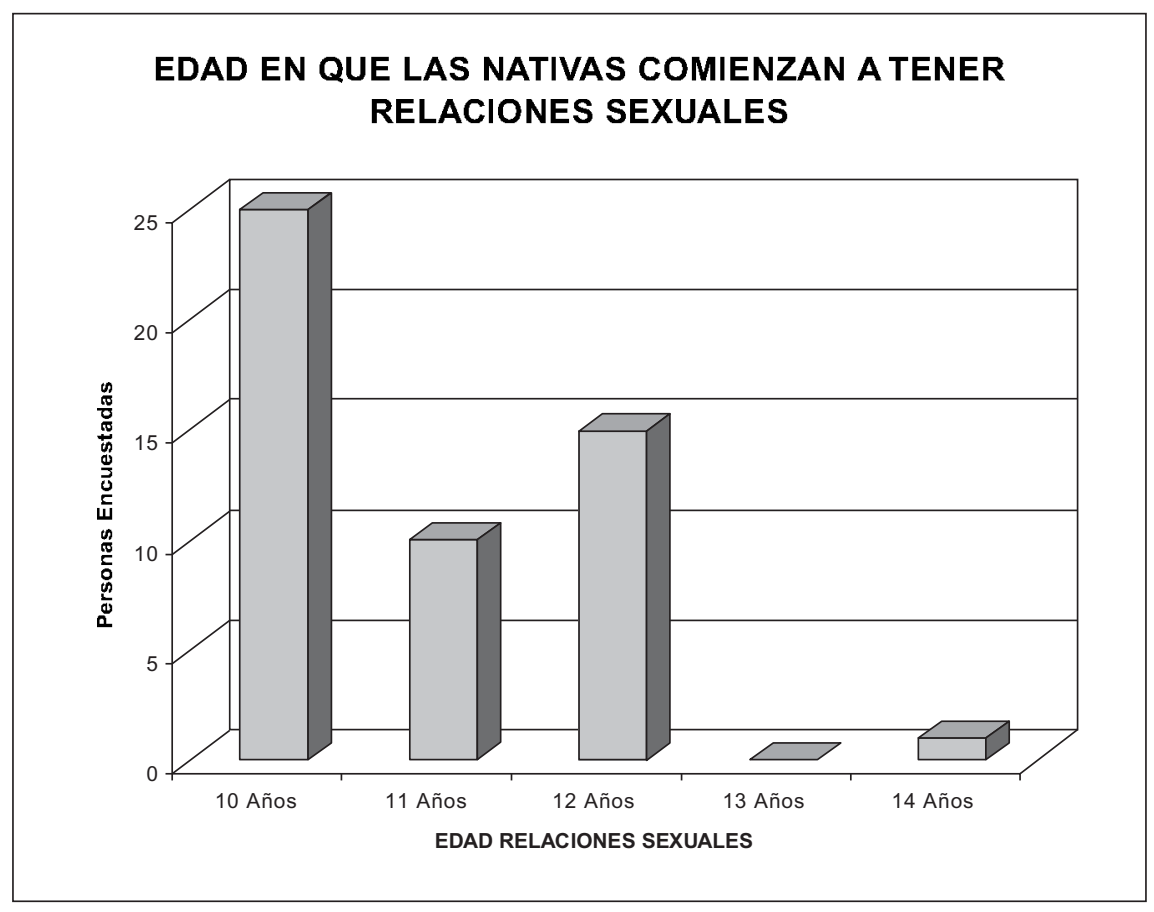


Jorge Cueva Zavaleta - Colisión de la ley penal y la costumbre en los delitos de violación sexual a menores de edad cometidos por los integrantes de las comunidades nativas de la cuenca del río Amazonas

CUADRO № 2. Muestra de 51 personas encuestadas quelaboraron en Comunidades Nativas, confirmando la edad en que las Nativas comienzan a tener hijos, en el Departamento de San Martín provincia de Lamas en Enero de 2007.

\begin{tabular}{|c|c|c|}
\hline $\begin{array}{c}\text { Edad de las N ativas que } \\
\text { comienzan a tener hijos }\end{array}$ & $\begin{array}{c}\text { No Personas } \\
\text { Encuestadas }\end{array}$ & Porcentaje \\
\hline 10 Años & 4 & 7.84 \\
\hline 11 Años & 4 & 7.84 \\
\hline 12 Años & 20 & 39.22 \\
\hline 13 Años & 11 & 21.57 \\
\hline 14 Años & 6 & 11.76 \\
\hline 15 Años & 3 & 5.88 \\
\hline 16 Años & 3 & 5.88 \\
\hline TOTAL & 51 & 100.00 \\
\hline
\end{tabular}

FUENTE: Encuesta de 51 personas que Iaboraron en Comunidades $\mathrm{N}$ ativas de San Martín (Lamas - Motilones)

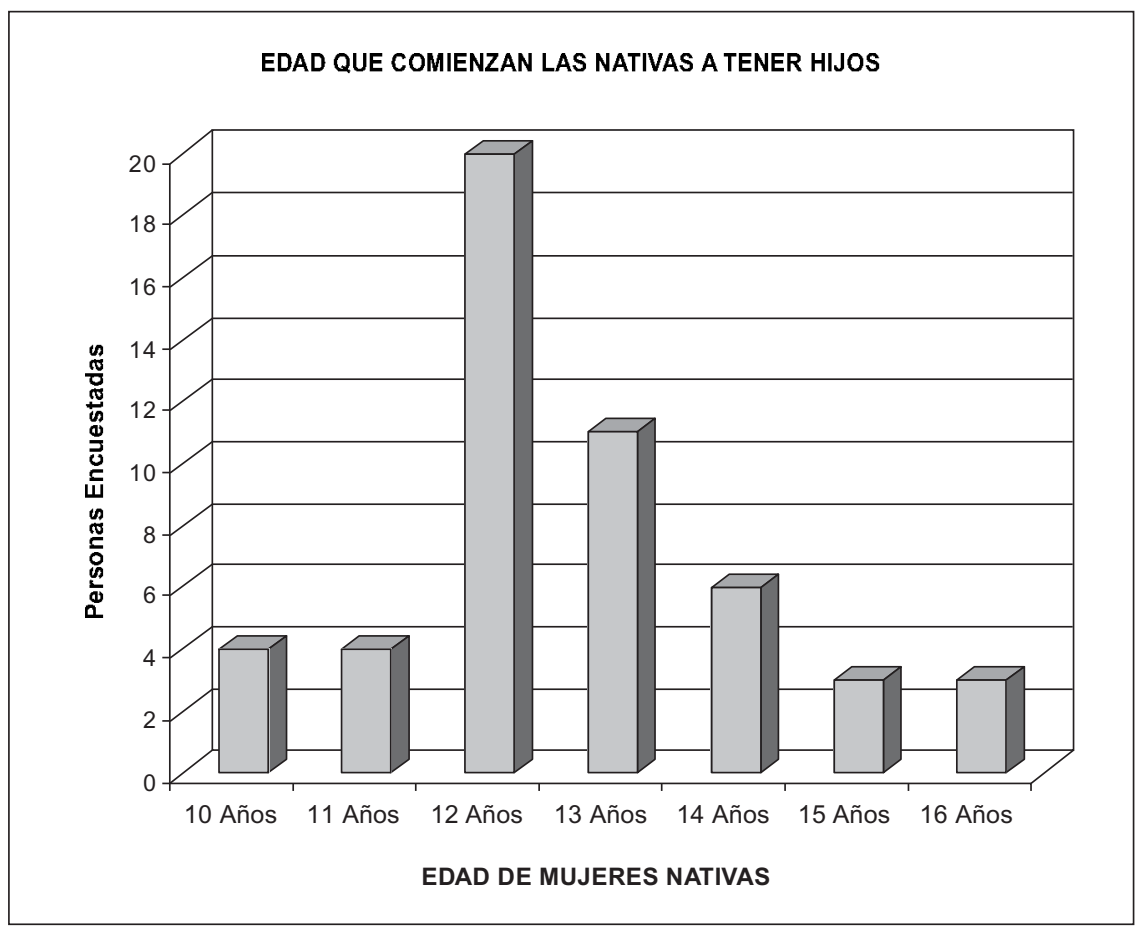


Jorge Cueva Zavaleta - Colisión de la ley penal y la costumbre en los delitos de violación sexual a menores de edad cometidos por los integrantes de las comunidades nativas de la cuenca del río Amazonas

CUADRO № 3. Muestra de 51 personas encuestadas quelaboraron en Comunidades Nativas, confirmando en que corresponden a sus propias costumbres, en el departamento deSan Martín provincia de Lamas en Enero de 2007.

\begin{tabular}{|c|c|c|}
\hline $\begin{array}{c}\text { Corresponden a sus propias } \\
\text { costumbres }\end{array}$ & $\begin{array}{c}\text { No Personas } \\
\text { Encuestadas }\end{array}$ & Porcentaje \\
\hline Sl & 51 & 100.00 \\
\hline NO & 0 & 0.00 \\
\hline TOTAL & 51 & 100.00 \\
\hline
\end{tabular}

FUENTE: Encuesta de 51 personas que laboraron en Comunidades Nativa de San Mártir (Lamas - Motilones)

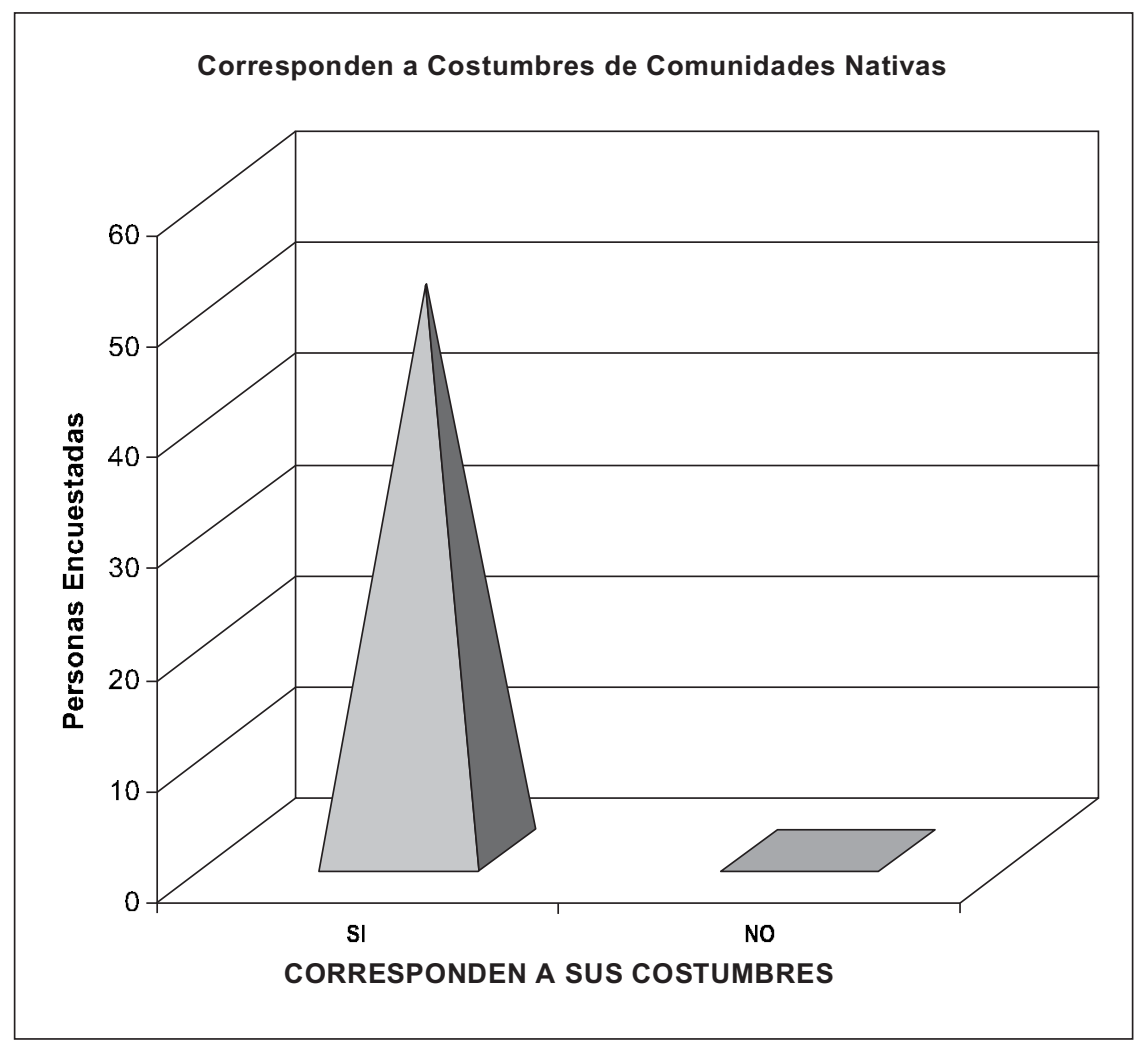


Jorge Cueva Zavaleta - Colisión de la ley penal y la costumbre en los delitos de violación sexual a menores de edad cometidos por los integrantes de las comunidades nativas de la cuenca del río Amazonas

CUADRO № 4. ResolucionesJudiciales: procesos por delito deViolación Sexual de menor de edad según el Art. 173 inc. 3 del Código Penal a la cultura mayoritaria Mestiza y minoritaria Nativa.

Violación Sexual de Menor deEdad

\begin{tabular}{|c|c|}
\hline \multicolumn{2}{|c|}{ Resoluciones Judiciales } \\
\hline Cultura Minoritaria ( Nativa) & cultura mayoritaria ( mestiza ) \\
\hline 2 & 19 \\
\hline
\end{tabular}

FUENTE: Procesos Tramitados en las Corte Superiores de Loreto y La Libertad.

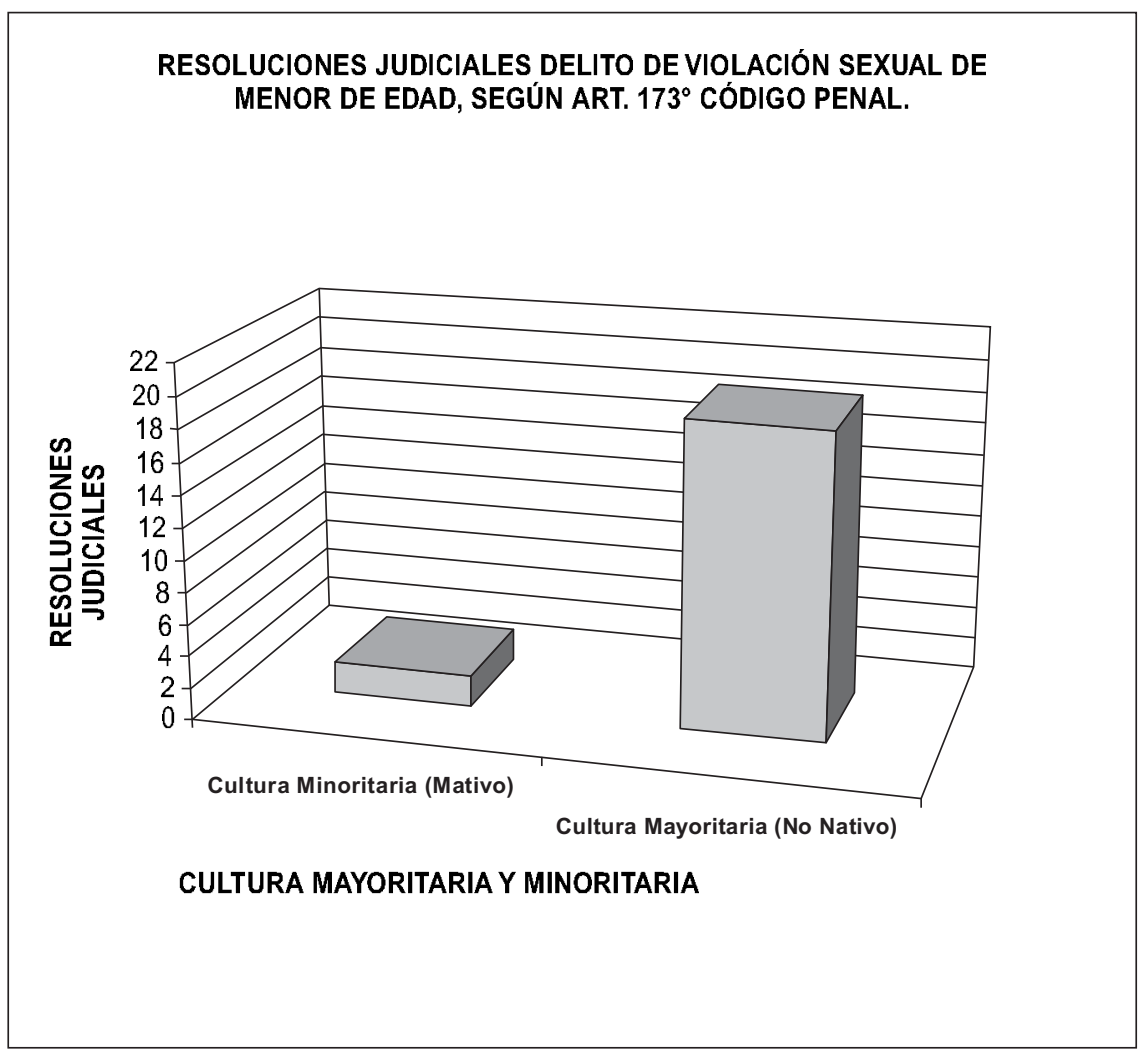


Jorge Cueva Zavaleta - Colisión de la ley penal y la costumbre en los delitos de violación sexual a menores de edad cometidos por los integrantes de las comunidades nativas de la cuenca del río Amazonas

\section{IV.DISCUSIÓN}

Como lo sostiene Silva, una legislación sustantiva y procesal uniforme no da lugar a un Derecho uniforme ${ }^{12}$. En el Perú la Ley Penal se aplica en todo el territorio nacional, sin considerarsequees un país multicultural y quelas culturas que habitan en su territorio se interrelacionan entre sí. A sí mismo, las culturas nativas de la cuenca del río A mazonas, tienen sus propias costumbres que rigen su forma de vida, como la práctica de convivencia sexual con menores de edad. Esto se demuestra con la encuesta realizada a personas que laboraron en las Comunidades N ativas de San M artín y Loreto, quienes confirmaron que corresponden a sus propias costumbres. Así mismo, el $49 \%$ de los encuestados que laboraron en dichas comunidades, confirmaron que las mujeres nativas comienzan a tener relaciones sexuales a la edad de 10 años, un $19.61 \%$ a los 11 años, y un $29.41 \%$ a los 12 , por lo queel promedio deinicio dela vida sexual es de 11 a 12 años de edad (ver cuadro № 1). Esto se corrobora con los resultados del cuadro número dos, en el que los encuestados confirman que las nativas comienzan a procrear sus hijos a los 12 años de edad.

De otro lado, se obtuvieron resul tados que se relacionan con los procesos Il evados a cabo en la Corte Superior de Justicia de Loreto contra nativos de las Comunidades Nativas dela Cuenca del río A mazonas, como el caso penal $\mathrm{N}$ o 2005-87-Loreto seguido contra Mario Nashnate Tamanta, pertenecientea la comunidad nativa de Palizada- Pampa Caño río M arañón (del grupo étnico Aguaruna), por el delito contra la Libertad SexualViolación demenor de edad, previsto en el artículo 1730 inciso 3 del Código Penal Vigente, a quien se le impuso 15 años de pena privativa de la libertad mediante sentencia de fecha 22 de noviembre de 2006, sustentándose la misma en el octavo considerando que "para los efectos de graduarse la pena debe tomarse en cuenta las circunstancias como ocurrieron los hechos, las costumbres y medio de vida del lugar donde se produjeron los hechos (selva peruana, donde las familias viven de la caza y de la pesca, y donde el despertar sexual de las personas es a temprana edad), el bajo nivel cultural del acusado...." . En otro caso estudiado, en el proceso penal $\mathrm{N}^{\circ}$ 2005-00106- Loreto, seguido contra Santos Vela M ejía por el delito contra la Libertad Sexual- violación sexual de menor de edad, tipificado en el artículo 173o inciso 3 del Código Penal, el acusado es un miembro de la Comunidad Nativa de Pijuayal- río Chambira- Urarina a quien el representante del Ministerio Publico esta solicitando se le imponga la pena 
Jorge Cueva Zavaleta - Colisión de la ley penal y la costumbre en los delitos de violación sexual a menores de edad cometidos por los integrantes de las comunidades nativas de la cuenca del río Amazonas

privativa de la libertad de 20 años, sin considerar su cultura y costumbres ancestrales muy diferentes a los de la cultura mayoritaria mestiza ni a sus organismos de resolución de conflictos. Al respecto, Figueroa, sostiene que los derechos de las comunidades nativas no son derechos individuales sino derechos reconocidos a los puebl os indígenas y sus comunidades, un sujeto de derecho diferente a las personas individual $\mathrm{es}^{13}$. Así mismo, se obtuvo resultados de procesados de la cul tura mayoritaria mestiza por el delito contra la Libertad Sexual- Violación sexual de menor de edad, tipificado en el artículo 173o inciso 3 del Código Penal. Con ello se demuestra que tanto a nativos como a mestizos se aplica la misma ley penal, sin diferenciar que los primeros actúan deacuerdo a sus costumbres ancestrales y que existen organismos de resolución de conflictos en sus comunidades, aunado al hecho de que las penas que se imponen en las sentencias condenatorias son tan drásticas como a los mismos mestizos. Lo anterior no hace sino confirmar la hipótesis formulada, pues la ley penal y la costumbre colisionan cuando se procesan a los nativos de las comunidades de la cuenca del río A mazonas por el delito de violación sexual de menores de edad. En ese sentido, estamos de acuerdo con Villavicencio, cuando sostiene que la concepción de una justicia unitaria es evidente para una idiosincrasia europea moderna, mas no para Estados con fuertes derechos consuetudinarios locales y étnicos y sistemas informales de justicia ${ }^{14}$; opinión que guarda coherencia con Donayre. al comentar éste la Carta Andina de Derechos Humanos: "Asimismo se reconoce el derecho a la identidad, propiedad, posesión de tierras o territorios que tradicional mente ocupan y a no ser desplazados de ell os; a conservar sus formas propias de organización, ejercicio de autoridad y administración dejusticia; a desarrollar y mantener su patrimonio cultural, artículo $38^{\circ}$ de la Carta en referencia" ${ }^{15}$. En ese orden de ideas, se hace necesario la elaboración y promulgación deun Código Penal Especial para las comunidades nativas basado en sus costumbres ancestral es que rigen su forma de vida, así como sus organismos de resolución de conflictos. No siendo suficiente lo establecido en el artículo 150 del Código Penal que regula el error de comprensión cultural mente condicionado.

\section{V.CONCLUSIONES}

1. La Ley Penal y la costumbre colisionan cuando se procesan a los nativos de las comunidades de la cuenca del río A mazonas por el delito de violación sexual tipificado en el artículo 173으 del Código Penal, a pesar 
Jorge Cueva Zavaleta - Colisión de la ley penal y la costumbre en los delitos de violación sexual a menores de edad cometidos por los integrantes de las comunidades nativas de la cuenca del río Amazonas

de que la convivencia con menores de edad corresponden a sus costumbres ancestrales que rigen su forma de vida.

2. La Ley Penal Unitaria se aplica en todo el territorio del Perú, sin considerar que es un país multicultural e intercultural y que se hace necesario la elaboración y promulgación de un Código Penal Especial, en base a las costumbres y organismos de resolución de conflictos delas comunidades nativas.

3. Entre las costumbres ancestrales de las comunidades nativas se encuentra el inicio temprano delas relaciones sexual es delos miembros de las Comunidades Nativas con menores de su propia comunidad, cuyas edades oscilan entre los 11 y 12 años de edad, determinando que el $72.55 \%$ de las mujeres inicien la procreación de 12 a 14 años de edad.

4. En los procesos penales de violación sexual de menores, seguidos en la Corte Superior de Justicia de Loreto, lo jueces no hacen distingos al momento de determinar la pena a imponerse a los miembros de las comunidades nativas, dictándose sentencias drásticas tan igual como a los procesados pertenecientes a la cultura mayoritaria.

5. Existe un error de prohibición especial en el Código Penal, regulado en el artículo 15o, que resulta discriminatorio al considerar que los nativos proceden por error de comprensión culturalmente condicionado más no por sus costumbres ancestrales.

1 Hurtado, J. M anual de D erecho Penal, Parte General I. Lima. Grijley, 2005. Pág. VII.

2 Malgesisni y Gimenez. "Guía de conceptos sobre migraciones, racismo e interculturalidad". \{http:/ / solidaridad.universia.es/ aula/ otrosconceptos.htm\}, Trujillo 14 de mayo de 2007.

3 Perú Ecológico. Pueblos Indígenas A mazónicos. \{www. perúecológico.com.pe/ etnias_mapa]. Trujillo, 28 de julio de 2007.

4 Lo nuevo en ENJOY Perú. Lamas, Los M otilones y sus Ancestros [www.enjoyperú.com/ lo-nuevo-en-enjoyperu/ lamas-los-motilones-y-sus-ancestros] Lima, 27 de Julio de 2007.

5 Villavicencio F. D erecho Penal Parte G eneral. Lima: Grijley, 2006. Pág. 148.

6 Depósito de documentos de la FAO. U na educación en población para la juventud rural a nivel comunitario. \{www. fao.org/ docrep/ x5633s/ x5633sOm.htm\}, Trujillo, 02 de julio de 2007.

7 Ibidem. Pág. 152.

8 Peña J. Pluralismo Jurídico en el Perú. En Desfaciendo Entuertos. Medios alternativos de resolución de conflictos: 1994; Boletín: 3-4: 13.

9 Martinez, R. Insuficiencia del A rtículo 15 del Código Penal. En Actual idad Jurídica-Gaceta Jurídica, 2007; Tomo 161: 105 -108.

10 Ibidem. Pág. 637.

11 Ibidem. Pág. 625.

${ }^{12}$ Silva, J. G lobalización y D erecho Penal . En Revista Jurídica del Colegio de A bogados de La Libertad. 2006; № 139: 60 . 
Jorge Cueva Zavaleta - Colisión de la ley penal y la costumbre en los delitos de violación sexual a menores de edad cometidos por los integrantes de las comunidades nativas de la cuenca del río Amazonas

13 FIGUEROA, V. Los Pueblos Indígenas: ¿V iejos o nuevos sujetos de derechos en la legislación A rgentina? Revista I uris Lex Societas de Trujillo. 2006; Año I N o 1: 95

14 Ibidem. Pág. 148

15 DONAYRE, M. ¿Nueva Carta de Navegación? Declaración A mericana de Pueblos Indígenas. EI persuasivo Soft Law Indígena. Lima: Editorial Horizonte, 2005. Pág. 44. 